\title{
Innovative Qualities of Today's Young Students (As Exemplified by the Siberian Federal University)
}

\author{
Anastasia V. Kistova \\ Natalia N. Pimenova \\ Ksenia V. Reznikova* \\ Natalia N. Seredkina \\ Julia S. Zamaraeva \\ Siberian Federal University, Russian Federation \\ *Corresponding Email: k-reznikova@inbox.ru
}

\section{Doi:10.5901/mjss.2015.v6n6s7p262}

\section{Abstract}

This paper looks into young people's attitudes to innovation. It goes without saying that being innovative is more than just an adaptation tool in a modern society; it is also a personal characteristic allowing one to be an active participant in innovation processes. This is an attempt to study innovative qualities found in today's young students of the humanities and technology. The study was conducted using the Self-Assessment Innovation Scale (a method designed by N. M. Lebedeva and A. N. Tatarko). The key idea of this method is to gauge a person's propensity towards innovation by self-assessing their innovative qualities. The study revealed that most students have a medium level of innovativeness; just under a third, a high level; and 1-5\%, a low level. Regardless of their level of innovativeness, humanities students showed a dominating presence of creativity: not only are medium innovativeness humanities students creative, they are also more future-oriented. At the same time, they prefer to avoid risk-taking. When it comes to technology students of any kind, creativity is not their dominant feature. Yet high innovativeness technology students are almost as prone to risk-taking as they are likely to be creative. Tech students with a medium level of innovativeness are more future-oriented than any other group of respondents, but they are no strangers to creativity either. The overall level of innovativeness appears to have little to do with a student's area of training. This may suggest that innovativeness on the whole has more to do with a student's college rather than their line of study. But to confirm or debunk this theory, one would have to run similar studies among students of other Krasnoyarsk colleges.

Keywords: Innovative qualities, Self-Assessment Innovation Scale method, young students, creativity, innovativeness

\section{Introduction}

Innovation processes have become an integral part of today's ever-changing world. These days they reach far beyond the world of economics and penetrate the very fabric of society, which is why studying innovation in the humanities seems like an appropriate subject for this day and age. Following decades of active integration into the realm of sociocultural practices, innovation processes have rooted themselves into our everyday lives and laid the foundation for nurturing certain personal qualities and values. Aspiring to develop and create something new, embracing innovation, and being ready to update one's methods and sociocultural environment, which is what innovativeness is all about are among the key challenges of our time and some of the things that society requires from a modern individual. Innovativeness is a very personal quality that helps one get involved in an innovative society not only by adapting to it, but also by becoming an active participant in social processes. This paper looks into innovative qualities found in today's young students of the humanities and of technology.

\section{Literature Overview}

Individual attitudes to innovation have seen a fair amount of attention in the past decade. Most studies of this subject fall into one of these three distinct categories: defining and testing methodological tools for studying innovation (mainly in sociology and cross-cultural psychology); developing innovation-related concepts and definitions; presenting results of 
applied research into an individual's attitude to innovation. Gerometta et al. (2005), Prigulny (2007), Kotelnikova (2012), Burns and Krampf (2015), Kirko et al. (2012), Glor (2015a; 2015b), Baker and Mehmood (2015), Baumgarten (1975) research the methodology of innovation and try to define its varieties and types. Taylor, (1970), Carlson et al. (1971), Zhuravskaya (2008), Fujisawa et al. (2015), Kuehlwein and Rosen (1993) look into the foundations of systemic analysis of innovation, including systemic component, systemic structural, and systemic functional approaches. An article by Kroytor (2011) suggests the unique concept of studying innovation on three levels: societal, institutional, and personal. Kuchko (2012) sheds light on the role and potential of sociological research in studying innovation practices and discusses the need for complex research into innovation which would involve a range of methods.

Jacoby (1971), Madrid et al. (2014), Nesterov (2007), Orlova (2013), Baranova (2012), Herrera (2015), and Zagashev (2010) have all contributed their innovation-related concepts and definitions in recent years. These researchers believe that innovation is a psychological characteristic defining one's readiness to embrace today's modernization of life and affecting one's day-to-day activities. Zagashev (2010) suggests a typology of innovation readiness and matches it with phases of the innovation cycle. He also develops a psychological view on the concepts of "innovation", "innovative management", and "innovation readiness". Nesterov (2007) turns his attention to studying the concepts of "innovation", "innovative activities", and "innovation potential". An article by Orlova (2013) presents "innovation" as a sociocultural category that is vital for studying microdynamic processes in society and culture. Baranova (2012) reviews approaches to defining innovation as a category and reveals interrelations between the concepts of "innovation", "innovative activities", and "innovation potential" when viewed from the process approach.

Russia's innovation policy is actively changing today's sociocultural reality. This is why researchers believe it is important to keep track of whether innovation processes affecting people's outlooks have any success. First of all, research should be made into young people's innovativeness and it's potential. Strelkov et al. (2010) have come up with a systems analysis method to study modernization as a process of generating innovation and suggested a set of methods for evaluating higher education institutions' performance. Shapovalova (2013) believe that young college students' innovation readiness is an important condition of initiating and implementing innovation in a modern-day higher education institution. Moskvich and Viktoruk (2011) suggest that today's college students display a fairly high level of innovative activity. Volobueva (2012) looks at young people's attitude to innovation through the prism of their resilience to the everchanging modern world and its conditions. According to this author, there is a link between the innovativeness index and the level of resilience: the higher the resilience, the higher the innovativeness. Shcherbakova (2006) looks into resistance to corporate innovation and suggests a classification of the forms and varieties of resistance and a measurement tool for prospective resistance to corporate innovation. Abramov and Zudina (2010) have studied the behavior of social innovators whose life circumstances and biography prompted them to experiment with emerging institutional opportunities and to take advantage thereof. Basilyan (2013) in her analytical review of a 2011 nationwide survey suggested that Russian people have a mixed understanding and perception of innovation. "On the one hand, this is a cultural thing: Russians are moderate collectivists who tend to work in hierarchical teams with strict rules and subordination; they don't like taking risks or taking action when faced with uncertainty. On the other hand, people are not that well informed about innovation and tend to associate it with capital and finance only" (Basilyan, 2013, p. 130).

Some researchers look into how various cultural practices affect innovative activities. For example, Lungeanu and Contractor (2015) have studied the gender factor in generating innovative ideas; while DiRienzo and Das (2015) have analyzed the role of ethnic and religious diversity in innovation. According to these authors, ethnic diversity weakens innovation, whereas religious diversity makes a positive contribution. Gulbrandsen and Aanstad (2015), Hofman (2013), McElroy (2002), Moulaert et al. (2007), Wisse et al. (2015) and others turn their attention to innovation and the world of the humanities, such as promoting innovation in universities or the arts. Phills et al. (2008), Moon et al. (2008), Smith and Seawright (2015) study innovative behavior in the aspect of consumer behavior and marketing. Ilbeykina et al. (2015) analyze by social innovation in the city of Krasnoyarsk (Central Siberia). Koptseva and Kirko (2014a; 2014b; 2015) research innovation processes within Northern and Siberian native communities and suggest ways of increasing innovative activities among these unique ethnocultural groups. Suslov (2013) also suggests a number of strategies to boost innovative activities in Siberia. Koptseva (2014), Libakova et al. (2014), Zamarayeva et al. (2015) refer to field research to uncover the living conditions of today's Northern and Siberian indigenous peoples and their innovative activities which are vital for improving their quality of life. The results of field research conducted by Reznikova et al. (2014) prove that people living in Northern and Arctic areas are still able to implement their innovation potential within a traditional economy based on reindeer herding, hunting, and fishing.

As of today, a lot of research has been conducted into the innovative qualities of Siberian people. But college students' innovation potential failed to attract as much attention. Meanwhile, students are the very people who soon will be defining new possible paths for Russia's Northern and Siberian regions. It is important to understand which 
psychological features found in Siberian Federal University students predetermine their readiness to innovate in the economy, society, and culture.

\section{Research Methodology}

The research was conducted using questionnaires as the primary method. It also employed the Self-Assessment Innovation Scale by Lebedeva and Tatarko (2009). The key idea of this method is to gauge a person's propensity towards innovation by self-assessing their innovative qualities. The authors identified a number of characteristics that help people stay positive towards innovation and get involved in the innovation process. These characteristics were used to design a test which asks respondents to indicate how much they resemble this kind of person and rate 12 statements on a scale from 1 ("not at all like me") to 5 ("very much like me") (Table 1).

Table 1. Test for Students about Innovative Qualities

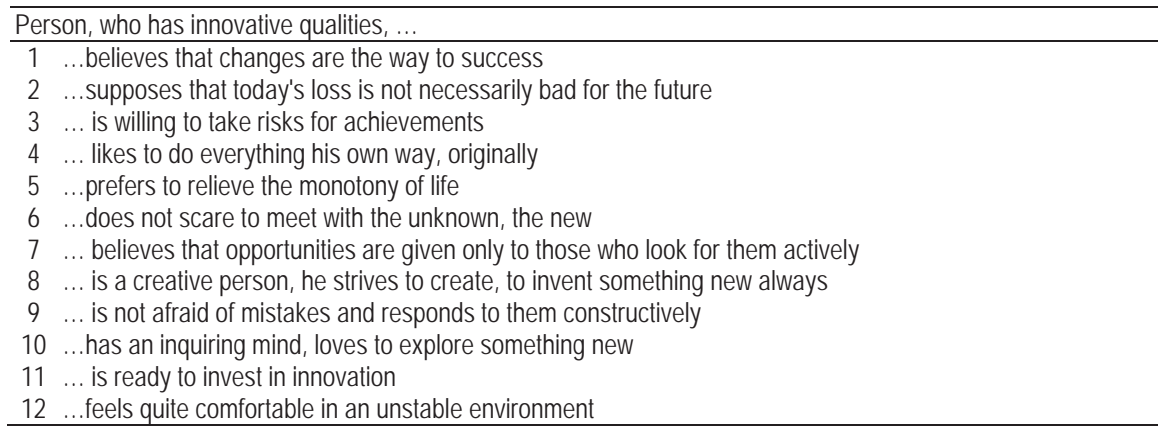

Source: the Self-Assessment Innovation Scale, based on (Lebedeva \& Tatarko, 2009)

Note: questions are ranked as follows: 'Not at all like me', 'Not like me', 'A bit like me', 'Like me', 'Very much like me'.

The statements were then grouped under three major factors: creativity (questions 4, 5, 8, 10), risk-taking (questions 3, 6 , 11, 12), and future orientation (questions 1, 2, 7, 9). Bartlett's Sphericity Test and the KMO Index (Kaiser-Mayer-Olkin) were used to measure the applicability of this factor structure. Then the questions from each category were put together into scales, and Cronbach's $\alpha$ was calculated to estimate the reliability and correlation of the resulting scales. The method was used to survey 186 Siberian Federal University students pursuing the humanities (95 respondents: 21 males and 74 females) or technology (91 respondents: 84 males and 7 females) in March 2015. The following stage of research involved factor analysis, result interpretation, and introspection (self-analysis).

\section{Findings and Discussion}

By surveying 186 Siberian Federal University students and distributing the results between factor-based humanities and technical tables, we were able to calculate the arithmetical average for both respondent groups in each of the three factor categories (creativity, risk-taking, and future orientation) and identify their overall innovativeness. The results are shown in Table 2.

Table 2. Innovativeness Indexes for Humanities and Technology Students

\begin{tabular}{lcccc}
\hline & Creativity & Risk-Taking & Future Orientation & Innovativeness Index \\
\cline { 2 - 5 } Humanities Students & $\mathbf{3 . 8 2}$ & $\mathbf{2 . 9 4}$ & 3.42 & 3.39 \\
Tech Students & 3.46 & 3.14 & 3.37 & 3.32 \\
\hline
\end{tabular}

The overall innovativeness index (just like the other three indexes for creativity, risk-taking, and future orientation) can range between 1.00 and 5.00, hence the entire scale can be split into three equal parts: low, medium, and high level.

Given that (5.00-1.00):3=1.3(3), the following ranges apply to each of the levels: 
- Low level: $1.00-2.33(1.00+1.33=2.33)$.

- Medium level: $2.34-3.67(2.34+1.33=3.67)$.

- High level: 3.68-5.00.

Using the above scale to interpret the results from Table 1, we can see that pretty much all the average indexes for both respondent groups fall into the medium level. The only index to break out of the medium level is creativity among humanities students. Interestingly, the same category of students also revealed the lowest risk-taking index. Therefore, humanities students have high levels of creativity, but tend to avoid risk-taking.

Another interesting observation is that the overall level of innovativeness does not depend strongly on a student's field of training (humanities: 3.39, technology: 3.32). This may suggest that the overall level of innovativeness has more to do with a student's college rather than their specific line of training. But to put this assumption to the test, one would need to run similar studies in other Krasnoyarsk colleges.

As we applied our multilevel scale (low, medium, and high levels) to each individual respondent rather than to their arithmetical averages, focusing on innovativeness indexes alone, we arrived at the conclusion that most students (that is, approximately two-thirds of our respondents) have a medium level of innovativeness, irrespective of whether they study humanities or technology; just under a third of respondents show a high level of innovativeness; and 1-5\%, a low level (see Table 3).

Table 3. Comparative Characteristics of Innovativeness Levels (in no. of people and \%)

\begin{tabular}{lcccc}
\hline & High Innovativeness & Medium Innovativeness & Low Innovativeness & Total Number of Respondents \\
\cline { 2 - 5 } Humanities Students & $24(25.26 \%)$ & $70(73.68 \%)$ & $1(1.05 \%)$ & 95 \\
Tech Students & $23(25.27 \%)$ & $63(69.23 \%)$ & $5(5.49 \%)$ & 91 \\
\hline
\end{tabular}

Let us move on to dedicated statistical data for each of the six subgroups (high innovativeness humanities students; medium innovativeness humanities students; low innovativeness humanities students; high innovativeness tech students; medium innovativeness tech students; low innovativeness tech students). Here we would like to focus specifically on determining which factor (creativity, risk-taking or future orientation) is most favored by respondents from each of the subgroups. To do this, we started by comparing each respondent's results against the three factors to identify their first, second, and third priority. Then we also counted how many respondents from each subgroup chose one factor or another as their first, second, and third priority. The results are given in Table 4.

Table 4. Students Priorities of Innovative Qualities (no. of people)

\begin{tabular}{|c|c|c|c|c|c|c|c|}
\hline & & \multicolumn{3}{|c|}{ Humanities Students } & \multicolumn{3}{|c|}{ Tech Students } \\
\hline & & Creativity & $\begin{array}{l}\text { Risk- } \\
\text { Taking }\end{array}$ & $\begin{array}{c}\text { Future } \\
\text { Orientation }\end{array}$ & Creativity & $\begin{array}{l}\text { Risk- } \\
\text { Taking }\end{array}$ & $\begin{array}{c}\text { Future } \\
\text { Orientation }\end{array}$ \\
\hline Priorities Among High & 1st Priority & 20 & 3 & 6 & 14 & 15 & 6 \\
\hline Innovativeness Students (no. & 2nd Priority & 4 & 7 & 14 & 6 & 5 & 11 \\
\hline of people) & 3rd Priority & 0 & 14 & 4 & 3 & 3 & 6 \\
\hline Priorities Among Medium & 1st Priority & 49 & 6 & 27 & 33 & 13 & 37 \\
\hline Innovativeness Students (no. & 2nd Priority & 18 & 23 & 33 & 25 & 26 & 17 \\
\hline of people) & 3rd Priority & 3 & 41 & 10 & 5 & 24 & 9 \\
\hline Priorities Among Low & 1st Priority & 1 & 0 & 0 & 2 & 2 & 3 \\
\hline Innovativeness Students (no. & 2nd Priority & 0 & 1 & 0 & 2 & 1 & 2 \\
\hline of people) & 3rd Priority & 0 & 0 & 1 & 1 & 2 & 0 \\
\hline
\end{tabular}

Having analyzed the number-one priority entries in Table 4, we have arrived at a number of important conclusions:

1. Whatever their innovativeness level (the low innovativeness group is not necessarily representative since it includes only one person), humanities students are far more likely to choose creativity as their top priority, followed by future orientation and risk-taking. Therefore, humanities students appear to be creative and futureoriented, but they are less prepared to take risk.

2. Creativity is a hands-down winner when it comes to high innovativeness humanities students, which is particularly clear when you compare the three top-priority factors: $20-3-6$. But when it comes to medium innovativeness humanities students, their top priority results do not differ so sharply: $49-6-27$. Therefore, medium innovativeness humanities students are not only creative, but also more future-oriented. 
3. The results for technology student subgroups are more diversified than those for humanities students. One of the things those three subgroups have in common though is that none of them identified creativity as their top priority, which is the opposite of what happened in all the three humanities subgroups. Therefore, creativity is not a dominant factor for any of the tech student subgroups.

4. Most high innovativeness tech students chose risk-taking as their number-one priority factor (15), whereas all the humanities student subgroups placed it only third. Creativity came second among high innovativeness tech students (14). Therefore, high innovativeness technology students are prone to risk-taking, but they also tend to be almost as creative.

5. Medium innovativeness tech students went for future orientation as their top priority (37), closely followed by creativity (33). Therefore, medium innovativeness technology students appear to be more future-oriented than any other subgroup, but they are no strangers to creativity either and have a medium tendency towards risktaking.

6. Tech students with a low innovativeness level (this is a poorly represented group including only 5 people) appear to be mainly future-oriented.

\section{Concluding Remarks}

The research we conducted allowed us to arrive at the following conclusions regarding innovativeness levels, creativity, risk-taking, and future orientation among students training for a career in the humanities or technology.

Whether they pursue humanities or technology, most surveyed students (about two-thirds of them) feature a medium level of innovativeness; just under a third have high innovativeness; and 1-5\%, low.

Creativity is the dominating quality for humanities students, irrespective of their level of innovativeness. Medium innovativeness humanities students are not only creative, but also more future-oriented. Also, humanities students are less likely to take risk.

Creativity is not a dominating factor for any of the tech student subgroups. High innovativeness technology students are prone to risk-taking almost as much as they are likely to be creative. Medium innovativeness tech students are more future-oriented than any other subgroup, but they are also no strangers to creativity. Their risk-taking level is medium. Low innovativeness tech students appear to be more future-oriented.

A student's line of study has very little bearing on their overall innovativeness level. This may suggest that innovativeness has more to do with a student's college rather than their field of study. But to put this assumption to the test, one would have run similar studies in other Krasnoyarsk colleges.

\section{Acknowledgment}

The publication was prepared within the framework of the project Krasnoyarsk Krai Foundation for Support of Scientific and Technical Activity.

\section{References}

Abramov, R. N., \& Zudina, A.A. (2010). Social innovators: Leisure practices and cultural consumption. The Public Opinion Monitor: Economic and Social Changes, 6 (100).

Agranovich, V. B. (2008). What the concept of innovation holds as a sociophilosophical category. News of the Tomsk Polytechnic University, 6, 312.

Baker, S., \& Mehmood, A. (2015). Social innovation and the governance of sustainable places. Local Environment, 20(3), 321-334.

Baranova, E. S. (2012). Category correlation in innovation studies. The Transbaikal State University Gazette, 2, $125-128$.

Basilyan, A. A. (2013). How Russian people perceive innovation and the innovation climate. The Public Opinion Monitor: Economic and Social Changes, 6 (118), 127-138.

Baumgarten, S. A. (1975). The innovative communicator in the diffusion process. Journal of Marketing Research, 12-18.

Burns, D. J., \& Krampf, R. F. (2015). A semiotic perspective on innovative behavior. In Proceedings of the 1991 Academy of Marketing Science (AMS) Annual Conference (pp. 32-35). Springer International Publishing.

Carlson, H., Thayer, R. E., \& Germann, A. C. (1971). Social attitudes and personality differences among members of two kinds of police departments (innovative vs. traditional) and students. The Journal of Criminal Law, Criminology, and Police Science, 564-567.

DiRienzo, Cassandra C., \& Das, J. (2015). Innovation and role of corruption and diversity: A cross-country study. International Journal of Cross Cultural Management, 15(1), 51-72.

Fateev, A. A. (2014). The concept of innovation readiness as a psychological issue. Part of: Science and education development prospects, a collection of scientific papers based on a Science Workshop: 5 parts. Moscow, Russia: OOO AR Konsalt. 
Fitjar, R. D. \& Rodriguez-Pose, A. (2011). Innovating in the periphery: Firms, values, and innovation in Southwest Norway. Working Papers Series in Economics and Social Sciences, 13. Accessed September 12, 2011 at: www.imdea.org.

Fujisawa, Y., Ishida, Y., Nagatomi, S., \& Iwasaki, K. (2015). A Study of Social Innovation Concepts: A Japanese Perspective. Japan Social Innovation Journal,5(1), 1-13.

Gerometta, J., Haussermann, H., \& Longo, G. (2005). Social innovation and civil society in urban governance: strategies for an inclusive city. Urban Studies,42(11), 2007-2021.

Glor, Eleanor D. (2015). Building Theory of Organizational Innovation, Change, Fitness and Survival. TIJ, 20 (2). Accessed May 20, 2015 at http://www.innovation.cc/books/20 2 1a glor fit organizations.pdf

Glor, Eleanor D. (2015). Review Essay of New Directions in Saskatchewan Public Policy and Remaining Loyal: Social Democracy in Quebec and Saskatchewan by David P. McGrane. The Innovation Journal: The Public Sector Innovation Journal, Volume 20 (1), article 7. Accessed May 20, 2015 at http://www.innovation.cc/book-reviews/20 17 glor rev-essy mc-grane.pdf

Gulbrandsen, M. \& Aanstad, S. (2015). Is innovation a useful concept for arts and humanities research? Arts and Humanities in Higher Education, 14 (1), 9-24.

Herrera, M. E. B. (2015). Creating competitive advantage by institutionalizing corporate social innovation. Journal of Business Research, 68(7), 1468-1474.

Hofman, R. H., de Boom, J., Meeuwisse, M., \& Hofman, A.W.H.L. (2013). Educational innovation, quality, and effects: An exploration of innovations and their effects in secondary education. Educational Policy, 27(6), 843-866.

Ilbeykina, M. I., Kolesnik, M. A., Libakova, N. M., Sertakova, E. A., \& Sitnikova, A. A. (2015). Global and Local Trends in Development of the Siberian City of Krasnoyarsk. Mediterranean Journal of Social Sciences, 6(3 S5), 241-248.

Jacoby, J. (1971). Personality and innovation proneness. Journal of Marketing Research, 244-247.

Kirko, V. I., Popodko, G.I., and Goloushkin, R.G. (2012). The mechanism of implementing the business model of open innovation for the involvement of potential of a closed city in the innovative development of the region. Journal of Siberian Federal University. Humanities \& Social Sciences, 5(7), 978-987.

Kistova, A. V., Pimenova, N.N.,. Zamaraeva, Y.S., \& Reznikova, K.V. (2014). Research possibilities for studying the indicators of quality of life of indigenous peoples of the North (based on the study of indigenous peoples of the North of Russia). Life Sci J, 11(6s), 593-600.

Koptseva, N. (2014). Expert analysis of the main trends of Northern Siberia's Indigenous small-numbered peoples economic development. Economic Annals-XXI, 11-12, 93-96.

Koptseva, N. P. \& Kirko, V.I. (2014a). Modern specificity of legal regulation of cultural development of the indigenous peoples of the Arctic Siberia under the global transformations. Life Sci J, 11 (9), 314-319.

Koptseva, N. P. \& Kirko, V.I. (2014b). The information basis for formation of positive ethnic identities in the process of acculturation of indigenous peoples of the Arctic Siberia (Krasnoyarsk, Russia). Life Sci J, 11(8), 479-483.

Kotelnikova, T A. (2012). On the issue of studying the effect of corporate behavior on creating innovation. Creative Economy, 1, 107111.

Kroytor, S. N. (2011). Sociological study of innovation: key categories and analysis levels. The Sociology Almanac, 2, $103-112$.

Kuchko, E. E. (2012). Sociological study of innovation. The Sociology Almanac, 3, 42-47.

Kuehlwein, K. T., \& Rosen, H. (Eds.). (1993). Cognitive therapies in action: Evolving innovative practice. Jossey-Bass.

Lebedeva, N.M. \& Tatarko, A.N. (2009). Methods of study relationship of the individual to innovate. Almanac of modern science and education, 4(23), P. II, 89-96.

Libakova, N. M., Sitnikova, A.A., Sertakova, E.A., Kolesnik M.A., \& Ilbeykina M.I.. (2014). Interaction of the Yakut ethnicity and biological systems in the territory of the Sakha Republic (Hordogoy settlement, Suntarsky District) and Krasnoyarsk Krai (Essey settlement, Evenks District). Life Sci, 11(6s), 585-592.

Lungeanu, A., \& Contractor N.S. (2015). The effects of diversity and network ties on innovations: The emergence of a new scientific field. American Behavioral Scientist, 59(5), 548-564.

Madrid, H. P., Patterson, M. G., Birdi, K. S., Leiva, P. I., \& Kausel, E. E. (2014). The role of weekly high-activated positive mood, context, and personality in innovative work behavior: A multilevel and interactional model. Journal of Organizational Behavior, 35(2), 234256.

Maksimenko, E. V. (2011). Preparing future social workers for innovation in professional activities, a dissertation. Kaliningrad, Russia.

Matveykin, V. G., Dvoretsky, S.I., Minko, L.V., Tarov, V.P., Chaynikova, L.N., \& Letunova, O.I. (2007). Innovation potential: Present state and future prospects, a monograph. Moscow, Russia: Mashinostroyeniye.

McElroy, M. W. (2002). Social innovation capital. Journal of Intellectual Capital,3(1), 30-39.

Mikhaylova, E. M. (2002). Systemic management of innovation processes in a higher education institution, a dissertation. Lipetsk, Russia: Lipetsk State University.

Moon, H., Kamdar, D., Mayer, D. M., \& Takeuchi, R. (2008). Me or we? The role of personality and justice as other-centered antecedents to innovative citizenship behaviors within organizations. Journal of Applied Psychology, 93(1), 84.

Moskvich, Y. N., \& Victoruk, E.N. (2011). Values of innovation for students, experts, and entrepreneurs in Krasnoyarsk: Desired ideal, hopes and reality. Journal of Siberian Federal University. Humanities \& Social Sciences, 11, 1507-1525.

Moulaert, F., Martinelli, F., González, S., \& Swyngedouw, E. (2007). Introduction: Social innovation and governance in european cities urban development between path dependency and radical innovation. European Urban and Regional Studies, 14(3), 195-209.

Mulgan, G. (2006). The process of social innovation. innovations, 1(2), 145-162. 
Nesterov, A. V. (2007). Innovation: A systemic approach. Competence, 6.

Orlova, E. A. (2007). The concept of innovation in sociocultural research. The Moscow Institute of State Management and Law Gazette, $33,83-88$

Phills, J. A., Deiglmeier, K., \& Miller, D. T. (2008). Rediscovering social innovation. Stanford Social Innovation Review, 6(4), 34-43.

Piskunov, P. I. (2013). Goal orientation as innovation as innovation readiness. Accreditation in Education, 2 (62), 76.

Prigulny, A. G. (2007). Methodology issues in innovation research. Economics and Management, 3, 38-43.

Robertson, T. S., \& Myers, J. H. (1969). Personality correlates of opinion leadership and innovative buying behavior. Journal of Marketing Research, 164-168.

Shapovalova, I. S. (2013). Today's Russian college managers and their readiness for innovation in higher professional education. News of the Southwest State University. Economy. Sociology. Management, 2, 118-125.

Shcherbakova, D. V. 2006. Resisting corporate innovation sociological research methodology. The Journal of Sociology and Social Anthropology, IX (4), 89-99.

Smith, I. H., \& Seawright, K. W. (2015). Social innovation through development franchising: compensating for a lack of entrepreneurial expertise and connecting to formal supply chains. In The Business of Social and Environmental Innovation (pp. 49-62). Springer International Publishing.

Strelkov, V. I., Lebedev, N.N., \& Usachyova, I.V. (2010). Innovation psychology as a motivation studies. Integral, (6), 129-131.

Suslov, V. I. (2013). Strategy of Siberia's development: From resource economy to innovation economy. Journal of Siberian Federal University. Humanities \& Social Sciences, 6(6), 940-950.

Taylor, J. B. (1970). Introducing social innovation. The Journal of Applied Behavioral Science, 6(1), 69-77.

The Oslo Guide: Guidelines for collecting and analyzing innovation data, 3rd edition. 2010. Moscow, Russia: Science Research and Statics Center, Ministry of Education and Science.

Uvarov, A. F., \& Osipov Y.M. (2006). Applying the concept of innovation within a training, science, and innovation complex. Innovation, 2.

Verdres, A. (2011). "Inventions and globalization: Innovation potential by countries". Accessed September 14, 2011 at: http://www.invention-ifia.ch.

Volobueva, N. M. (2012). Innovative qualities in young people with different resilience levels. Human. Community. Management, 4, 3945.

Wisse, B., Barelds, D. P., \& Rietzschel, E. F. (2015). How innovative is your employee? The role of employee and supervisor Dark Triad personality traits in supervisor perceptions of employee innovative behavior. Personality and Individual Differences, 82, 158-162.

Zagashev, I. O. (2010). Psychological innovation readiness as provision for effective quality control implementation. News of the Samara Scientific Centre of the Russian Academy of Sciences, 12(5-2), 418-420.

Zamarayeva, Y. S., Kistova, A. V., Pimenova, N. N., Reznikova, K. V., \& Seredkina, N. N. (2015). Taymyr Reindeer Herding as a Branch of the Economy and a Fundamental Social Identification Practice for Indigenous Peoples of the Siberian Arctic. Mediterranean Journal of Social Sciences, 6(3 S5), 225.

Zhuravskaya, N. T. (2008). On the issue of a systemic approach to studying innovation in college. The Tomsk State Teacher Training University Gazette, 3, 35-39. 